\title{
Development of opioid-induced constipation: post hoc analysis of data from a 12 -week prospective, open-label, blinded-endpoint streamlined study in low-back pain patients treated with prolonged- release WHO step III opioids
}

This article was published in the following Dove Press journal: Journal of Pain Research

10 August 2015

Number of times this article has been viewed

\author{
Michael A Ueberall' \\ Gerhard HH Mueller- \\ Schwefe ${ }^{2}$ \\ 'Institute for Neurological \\ Sciences, Nuremberg, Germany; \\ ${ }^{2}$ Interdisciplinary Center for Pain and \\ Palliative Care Medicine, Göppingen, \\ Germany
}

Background: Opioid-induced constipation is the most prevalent patient complaint associated with longer-term opioid use and interferes with analgesic efficacy, functionality, quality of life, and patient compliance.

Objectives: We aimed to compare the effects of prolonged-release (PR) oxycodone plus PR naloxone $(\mathrm{OXN})$ vs PR oxycodone (OXY) vs PR morphine (MOR) on bowel function under real-life conditions in chronic low-back pain patients refractory to World Health Organization (WHO) step I and/or II analgesics.

Research design and methods: This was a post hoc analysis of the complete data set from a prospective, randomized, open-label, blinded endpoint (PROBE) streamlined study (German pain study registry: 2012-0012-05; European Union Drug Regulating Authorities Clinical Trials [EudraCT]: 2012-001317-16), carried out in 88 centers in Germany, where a total of 901 patients requiring WHO step III opioids to treat low-back pain were enrolled and prospectively observed for 3 months. Opioid allocation was based on either optional randomization $(n=453)$ or physician decision $(n=448)$. In both groups, treatment doses could be adjusted as per the German prescribing information, and physicians were free to address all side effects and tolerability issues as usual. The primary endpoint was the proportion of patients maintaining normal bowel function throughout the complete treatment period, assessed with the Bowel Function Index (BFI). Secondary analyses addressed absolute and relative BFI changes, complete spontaneous bowel movements, use of laxatives, treatment emergent adverse events, analgesic effects, and differences between randomized vs nonrandomized patient groups.

Results: BFI changed significantly with all three WHO step III treatments, however significantly less with OXN vs OXY and MOR despite a significantly higher use of laxatives with the latter ones $(P<0.001)$. The percentage of patients who maintained normal BFI scores despite opioid treatment was $54.5 \%(164 / 301)$ with OXN and was significantly superior to those seen with OXY (32.8\% [98/300]) (odds ratio [OR]: 2.47, 95\% confidence interval [CI]: $1.77-3.44 ; P<0.001$ ) or MOR (29.7\% [89/300]) (OR: 2.84, 95\% CI: 2.03-3.97; $P<0.001)$. Absolute BFI changes of $\geq 12 \mathrm{~mm} 100 \mathrm{~mm}$ horizontal visual analog scale $\left(\mathrm{VAS}_{100}\right)$ vs. baseline were seen for OXN in $41.4 \%$, for OXY in $68.7 \%$, and for MOR in $72.3 \%$. Complete spontaneous bowel movements decreased at least by one per week in $10.3 \%$ with OXN vs $42.3 \%$ for OXY (OR: 6.39, 95\% CI 4.13-9.89; $P<0.001$ ) and 42.0\% for MOR (OR: 6.31, 95\% CI: 4.08-9.76; $P<0.001$ ). Overall, 359 treatment emergent adverse events (78 [OXN], 134 [OXY], and 147 [MOR]) in 204 patients
Correspondence: Michael A Uebera Institute for Neurological Sciences, Nordostpark 5I, 904II, Nuremberg, Germany Tel +49 9II 21773760 Fax +49 9II 21773761 Email michael.ueberall@ifnap.de 
(41 [OXN], 80 [OXY], and 83 [MOR]) occurred, most affecting the gastrointestinal (49.3\%) and the nervous system (39.3\%). Treatment contrasts between randomized vs nonrandomized patients were insignificant.

Conclusion: In this post hoc analysis of data from a real-life 12-week study, OXN treatment was associated with a significantly lower risk of opioid-induced constipation, superior tolerability, and significantly better analgesic efficacy compared with OXY and MOR.

Keywords: chronic pain, bowel function, quality of life

\section{Introduction}

Opioids are frequently used alternatives for the treatment of moderate to severe chronic nonmalignant pain in industrialized countries, second only to nonsteroidal anti-inflammatory agents in terms of prescription frequency. ${ }^{1-3}$ Beside analgesia, opioid therapy is associated with a number of well-characterized side effects, including constipation, nausea, sedation, dysphoria, itching, respiratory depression, and hormonal changes as well as immunological problems, which frequently develop in competition with analgesic effects. ${ }^{49}$

Among the spectrum of opioid-related adverse events, opioid-induced constipation (OIC) is the most frequently reported troublesome adverse event associated with chronic opioid therapy. ${ }^{10-12}$ Due to its persistence throughout opioid use, OIC is one of the main reasons for dose reduction, treatment failure, and premature treatment discontinuation, affecting approximately one-third of opioid-treated patients. ${ }^{12-15}$

Laxative regimens are recommended for clinical use, both to prevent and treat OIC. However, they are nonspecific, associated with several drawbacks (eg, bowel function muscle damage, nutritional deficits, kidney stones, renal failure, and/or interference with other drugs, etc), and are insufficiently effective in the majority of patients as they do not specifically address the underlying opioid receptormediated mechanisms of OIC..$^{10,16}$

More recently, few specific alternatives to prevent/treat OIC were developed, of which only naloxone - an opioid receptor antagonist - became available as a fixed prolongedrelease (PR) preparation with PR oxycodone (OXY) in a 1:2 ratio within one tablet (OXN), addressing the compliance and adherence problems of chronic pain patients with increasing tablet prescriptions. When administered orally, naloxone antagonizes the opioid-receptor activity of its counterpart, oxycodone, in the gut wall, while its PR formulation in combination with an extensive hepatic first-pass metabolism and subsequent low systemic bioavailability $(\sim 2 \%)$ ensures the lack of antagonistic effects on its central analgesic action..$^{17,18}$

Several randomized controlled trials (RCTs) evaluated safety and efficacy of OXN in comparison with OXY, and reported a significant and clinically relevant improvement in OIC in various types of pain, even after long-term treatment, without compromising pain control and drug safety in comparison with OXY. ${ }^{19-26}$ However, despite these measures, the overall safety and efficacy balance of OXN versus a conventional opioid therapy with OXY or morphine (MOR) (each plus laxatives), as first-line alternative in patients naïve to World Health Organization (WHO) step III opioids remains unclear. Due to this, the German Pain Association and the German Pain League initiated, in 2012, a prospective randomized open-label, blinded endpoint (PROBE), streamlined real-life study to evaluate the safety, tolerability, and efficacy of OXN in comparison with OXY and MOR in patients with chronic moderate to severe low-back pain (LBP) refractory to other analgesics, published recently by Ueberall and Mueller-Schwefe. ${ }^{27}$ In this study, half of the patients followed the randomized treatment allocation process, and their data - methodologically defined as those of the per-protocol population - was published, while the data of the remaining patients remained unconsidered and as such, free for further analyses.

\section{Patients and methods Study design}

The underlying 12-week study followed a PROBE design, developed to address some of the potential limitations of RCTs and observational studies. The main advantage of the PROBE trial design is the assessment of clinical outcomes in studies that allow both the enrollment of a broad patient population (in our case patients who require WHO step III opioid analgesics owing to a few refractory moderate to severe chronic LBP) as well as open-label, noninterventional dose adjustments and the discretionary use of concomitant laxatives, etc on an as-needed basis, which better reflects clinical practice and which also has the advantage of randomization and a rigorous evaluation of study endpoints by blinded data analyses. ${ }^{28,29}$ Opioid treatment followed medical requirements according to the decision of the participating physicians.

The study was performed using electronic case report forms for all data obtained by the participating physicians, as well as conventional paper-and-pencil pain questionnaires and diaries to obtain patient-reported data, throughout the whole 12-week observation period. Patient questionnaires/ 
diaries used were those recommended by the German Pain Association and the German Pain League, which cover a broad spectrum of validated instruments, addressing, among other parameters, pain intensity, pain-related disabilities in daily life, quality of life (QoL), QoL impairments from pain, bowel function, and use of analgesics and adjuvant therapies, etc. ${ }^{30,31}$

Regular study visits were scheduled at baseline (prior start of treatment), as well as after 4 (interim visit) and 12 weeks (end of observation visit). Optional, additional interim visits were possible at all times according to individual patient needs and established procedures (eg, if patients had to be closely monitored due to commencement of treatment, inadequate pain control, tolerability issues, and/or adverse events).

\section{Patients/study eligibility criteria}

Patients eligible for the study were males and nonpregnant, nonlactating females who were at least 18 years, with a documented history of moderate to severe, nonmalignant chronic LBP, previously treated with WHO step I or II analgesics with or without adjuvant treatments, who experienced either insufficient pain relief and/or unacceptable side effects and who required an around-the-clock therapy with any of the three mentioned WHO step III opioids. The exclusion criteria were those contraindications listed in the German prescribing information of the three opioid analgesics, ${ }^{32-34}$ addressing situations that would place the patient at risk upon exposure to the medication, and conditions that would confound the analysis and/or interpretation of the study results. Therefore, patients were excluded if they had previously shown hypersensitivity to any of the product constituents or if they had severe respiratory depression, chronic obstructive airway disease, pulmonary hypertension, severe bronchial asthma, paralytic ileus, moderate to severe hepatic impairment and/or renal impairment, or any other condition in which an opioid therapy is contraindicated. In addition, patients with irritable bowel syndrome, gastrointestinal (GI) disease, or significant structural abnormalities of the GI tract, who participated in a clinical research study involving a new chemical entity or an experimental drug within 30 days prior study entry, or in whom a surgery was planned during the scheduled observational period that would influence pain or bowel function, were excluded as well.

\section{Medication}

Based on the recommendations of the German National Association of Statutory Health Insurance Physicians and the Drug Commission of the German Medical Association, MOR, OXY, and OXN have been seen as comparably effective and therefore, at least from a medical point of view, interchangeable for the first-line treatment of opioidnaïve patients suffering from elsewhere refractory LBP. ${ }^{35}$ Therefore, an electronic treatment allocation system recommended one of these three alternative opioid treatments in a randomized 1:1:1 ratio (block size nine) after completion of the baseline evaluation by the physician and confirmation of a general treatment indication for a WHO step III opioid. To account for the noninterventional character of the original study, physicians were generally allowed to follow this recommendation or to choose alternatively one of the two other opioid treatments, which would exclude the patient from the per-protocol analysis of the randomized treatment allocations. The initial starting dose, dose titration, and further dose adjustments followed the recommendations given in the marketing authorization in existence at the time of the study and documented in the German prescribing information for those WHO step III opioids considered to be evaluated in this study. For opioid-naïve patients, the recommended starting dose was $20 \mathrm{mg}$ morphine equivalent (MEQ) of a PR preparation twice daily. Any dose adjustments, prescriptions of analgesic comedication, rescue medication, or laxatives were done at the discretion of the physician and due to the individual needs of the participating patients.

\section{Study assessments}

\section{Bowel function/opioid-induced constipation}

OIC was assessed using the validated Bowel Function Index (BFI), ${ }^{36,37}$ calculated as the mean of three items recorded retrospectively by patients for the previous 7 days, using a $100 \mathrm{~mm}$ horizontal visual analog scale $\left(\mathrm{VAS}_{100}\right)$, at the end of each treatment week. Single BFI items were: ease of defecation $(0=$ "easy/no difficulty" and $100=$ "severe difficulty"), feeling of incomplete bowel evacuation $(0=$ "not at all" and $100=$ "very strong"), and personal judgment of constipation $(0=$ "not at all" and 100= "very strong"). The BFI reference (ie, "normal") range is $0-28.8 \mathrm{~mm}$ on the $\mathrm{VAS}_{100}$, and BFI changes of $\geq 12 \mathrm{~mm}$ on the $\mathrm{VAS}_{100}$ were confirmed to be significant. In addition, the number of complete spontaneous bowel movements (CSBMs), defined as stools not induced by rescue medication or other external measures and associated with a sensation of complete evacuation, in the previous 7 days, and the use of laxatives as well as other pharmacological and nonpharmacological OIC counter measures, were documented to assess constipation. 


\section{Efficacy measures}

Efficacy assessments were performed on the basis of patientreported information documented in the German Pain Questionnaire $^{38}$ (at baseline) and the German Pain Diary (throughout the whole observation period) for pain intensity, pain-related disabilities in daily life activities/functionality, and QoL. Pain-intensity measures based on the LBP intensity index, which was calculated as arithmetic mean of the lowest, average, and highest 24-hour LBP intensities on a VAS $_{100}$ (where $0=$ "no pain" and 100= "worst pain conceivable"). LBP-related disabilities were assessed with a modified version of the Pain Disability Index (modified PDI), which recorded the degree of LBP-related functional restrictions on the basis of an eleven-point numerical rating scale $\left(\mathrm{NRS}_{11}\right)$ (where $0=$ "none" and $10=$ "worst conceivable") with respect to seven distinct domains of daily life. QoL was measured using the quality of life impairment by pain (QoL impairment by pain) inventory, a seven-question tool assessing different pain-related QoL restrictions that provides an overall QoLscore (ranging from $40=$ "no impairment" to $0=$ "maximum impairment"). All parameters were recorded by patients retrospectively for the previous 7 days, starting at baseline (to assess the situation prior onset of the WHO step III opioids) and covering the whole observation period, with regular assessments at the end of each treatment week.

\section{Safety and tolerability measures}

Safety assessment consisted of the monitoring of all treatment-emergent adverse events (TEAEs), collected as spontaneous reports and during patient visits. TEAEs were collected both through direct questioning by the physicians, as well as spontaneous patient reports and were recorded at each visit.

\section{Final assessment}

Final assessments of overall treatment satisfaction and patient condition (vs baseline, for each patient) were performed at the end of the 12-week observation period for each patient, using a seven-point clinical global impression of change scale ranging from +3 ("very much improved") to -3 ("very much worse") scored by the treating physician.

\section{Statistical analysis}

The aim of this post hoc analysis was to evaluate the dynamics, extent, and preventability of bowel dysfunction as consequence of a treatment with WHO step III opioids under real-life conditions, as well as to evaluate differences among those opioid analgesics used. The primary criterion for this approach was the treatment contrast for the frequency of patients maintaining a normal BFI score $(\leq 28.8)$ over the whole 12-week observation period. Secondary bowel tolerability aspects were the percentage of patients: with $\mathrm{a} \geq 50 \%$ BFI worsening at end of observation vs baseline; experiencing a clinically relevant BFI worsening vs baseline (ie, an increase $\geq 12 \mathrm{~mm} \mathrm{VAS}_{100}$ ); with a $\geq 1$ decline in the number of CSBMs per week; with $\geq 4$ CSBMs per week; and with prescribed laxatives at the end of the 12-week observation period. Secondary efficacy analyses were performed with respect to opioid-related changes in pain intensity, disability, and QoL, as well as treatment allocation effects between randomized and nonrandomized patients. Safety analyses addressed the percentage of patients with TEAEs and TEAErelated study discontinuation, as well as the spectrum and characteristics of the reported TEAEs.

Data analyses were performed for all enrolled patients (irrespective of the mode of treatment allocation) who took at least one dose of OXN, OXY, or MOR and who had at least one postbaseline/postdose measure. Due to the explorative post hoc character of this analysis, no formal sample size estimation was performed. Linear interpolation was used to impute intermittent missing scores, and the last observation carried forward method was used to impute missing scores after early discontinuation. For continuous variables, descriptive statistics were summarized by the number of patients (n), the mean, standard deviation (SD), 95\% confidence interval (CI), median, and range (minimum-maximum) values. For categorical and ordinal variables, data were summarized by the number (n) and percentage (\%) of participants in each category; where appropriate, 95\% CIs were added. For between-group comparisons of continuous/categorical variables, Student's $t$ /Pearson's chi-squared test, respectfully, were used. For within-group (eg, pre-post) comparisons, paired sample $t$-tests were performed. All statistical tests were carried out using a two-sided significance level of 0.05 . Test procedures were only used to evaluate the biometrical significance of differences found, not to confirm any a priori defined hypotheses.

\section{Ethics}

The original study was conducted in accordance with the principles of the Declaration of Helsinki and Good Clinical Practices, conformed to relevant national and local ethical as well as regulatory requirements, and was registered in the German pain study registry (Deutsche Gesellschaft für Schmerzmedizin [DGS]: 2012-0012-05) and the European Union Drug Regulating Authorities Clinical Trials (EudraCT) data base (EudraCT: 2012-001317-16). All patients provided 
written informed consent prior to study enrollment. The concept for this post hoc analysis was approved by the steering committees of the German Pain Association and the German Pain League.

\section{Results}

\section{Patient disposition}

Between April and August 2013, a total of 901 patients were enrolled, received treatment as assigned, and reported at least one postbaseline measure (Figure 1). Among 453 (50.3\%) patients, half were randomized to one of the three WHO step III opioids (144 [OXN], 151 [OXY], 158 [MOR]), whereas in $448(49.7 \%)$, treatment was assigned by the physician (157 [OXN], 149 [OXY], 142 [MOR]). Overall, significantly more OXN patients completed the study (225/301 [74.8\%]) compared with OXY (185/300 [61.7\%]) (odds ratio [OR]: 1.84, 95\% CI: $1.30-2.61 ; P=0.008$ ) and MOR (171/300 [57.0\%]) (OR: 2.23, 95\% CI: 1.58-3.16;

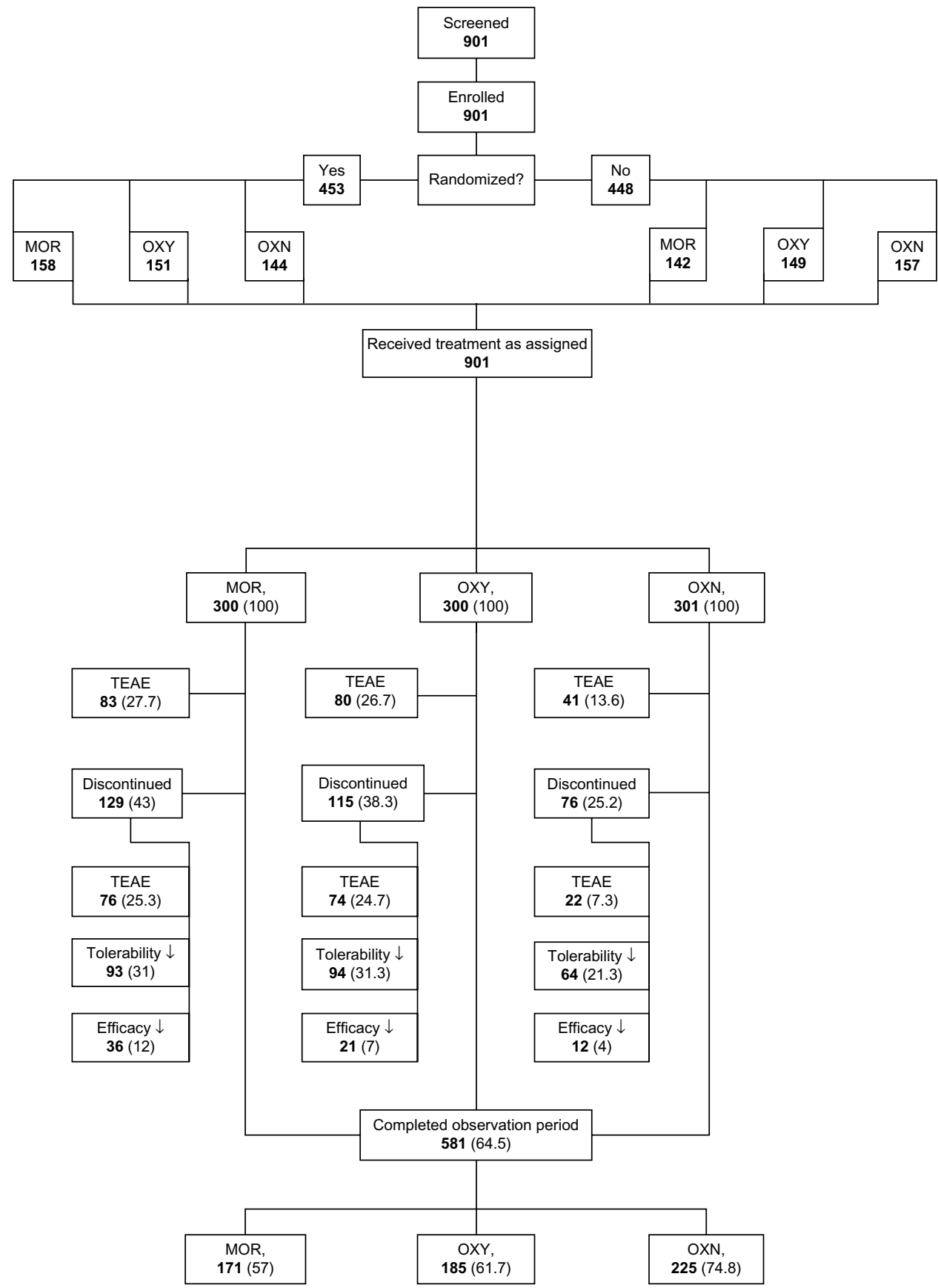

Figure I Patient disposition. Data is presented as $\mathrm{n}(\%)$ of patients. The arrows indicate insufficient numbers.

Abbreviations: \%, percentage of patients; MOR, morphine; $n$, number of patients; OXN, oxycodone/naloxone; OXY, oxycodone; TEAE, treatment emergent adverse event. 
$P=0.005)$. The main reason for premature discontinuation was insufficient tolerability, reported by 251 patients $(27.9 \%)$, followed by TEAEs (172/901 [19.1\%]) and insufficient analgesic efficacy (69/901 [7.7\%]). Between-group analyses showed comparable discontinuation rates for MOR (129/300 [43.0\%]) and OXY (115/300 [38.3\%]), which were - for all reasons evaluated - significantly worse than those observed with OXN (76/301 [25.2\%]) $(P<0.001)$. Corresponding comparisons of randomized vs nonrandomized patient groups were without any significant result.

\section{Baseline characteristics}

Baseline demographics were comparable between opioids and treatment allocation groups and are presented in Table 1.
Overall, the mean age $( \pm \mathrm{SD}$ ) was $46.3 \pm 9.7$ (median 47 , range 19-77) years, and 55.7\% (502/901) were female. A total of $58.8 \%$ (530/901) of study patients suffered for longer than 6 months prior study enrollment, 79.8\% (710/901) reported a treatment by at least five different specialists (average 5.6 \pm 1.4 [median 6, range 2-10]) and 94.0\% (847/901) of patients documented at least four analgesic medications (on average $6.3 \pm 1.9$ [median 6 , range 1-12]) at pretreatment. Nonopioid analgesics were the most frequently used treatments, reported by $99.0 \%$ (892/901) of patients prior study entry, followed by nonsteroidal anti-inflammatory drugs (NSAIDs) (95.3\% [859/901]), WHO-step II opioids (69.4\% [625/901]), antidepressants $(66.6 \%$ [600/901]), muscle relaxants $(63.2 \%$ [569/901]), and antiepileptic agents (37.1\% [334/901]).

Table I Patient demographics and baseline characteristics

\begin{tabular}{|c|c|c|c|c|c|}
\hline & \multicolumn{3}{|c|}{ Opioid treatment groups } & \multicolumn{2}{|c|}{$\begin{array}{l}\text { Treatment allocation } \\
\text { groups }\end{array}$} \\
\hline & $\begin{array}{l}\text { MOR } \\
(n=300)\end{array}$ & $\begin{array}{l}\text { OXY } \\
(n=300)\end{array}$ & $\begin{array}{l}\text { OXN } \\
(n=30 I)\end{array}$ & $\begin{array}{l}\text { RND } \\
(n=453)\end{array}$ & $\begin{array}{l}\text { nRND } \\
(n=448)\end{array}$ \\
\hline Age (years); mean (SD) & $46.5(9.3)$ & 46.7 (9.9) & $46.1(9.9)$ & $46.3(9.7)$ & $46.6(9.7)$ \\
\hline Proportion $>55$ years; $n(\%)$ & $56(18.7)$ & $57(19.0)$ & $56(18.6)$ & $76(16.8)$ & $93(20.8)$ \\
\hline Sex: female; n (\%) & $168(56.0)$ & $166(55.3)$ & $168(55.8)$ & $255(56.3)$ & $247(55.1)$ \\
\hline Height $(\mathrm{cm})$; mean $(\mathrm{SD})$ & $170.4(8.6)$ & $171.4(9.2)$ & $171.2(9.1)$ & $17||.(9.1)$ & $170.9(8.8)$ \\
\hline Weight $(\mathrm{kg})$; mean $(\mathrm{SD})$ & $79.4(17.7)$ & $79.5(15.8)$ & $80.2(15.5)$ & $79.6(16.3)$ & $79.8(16.5)$ \\
\hline BMI $\left(\mathrm{kg} / \mathrm{m}^{2}\right)$; mean (SD) & $27.3(5.9)$ & $27.0(4.5)$ & $27.4(5.0)$ & $27.1(4.7)$ & $27.3(5.5)$ \\
\hline Obesity (BMI >30.0); n (\%) & $63(21.0)$ & $62(20.7)$ & $65(21.6)$ & 91 (20.9) & $99(22.1)$ \\
\hline Low-back pain duration >6 months; $\mathrm{n}(\%)$ & $179(59.7)$ & $173(57.7)$ & $178(59.1)$ & $268(59.2)$ & $262(58.5)$ \\
\hline Number of physicians involved; median (range) & $6(2-9)$ & $6(3-10)$ & $6(2-10)$ & $6(2-10)$ & $6(2-10)$ \\
\hline Number of analgesics prior enrollment; median (range) & $6(I-12)$ & $6(1-12)$ & $6(I-12)$ & $6(I-12)$ & $6(I-12)$ \\
\hline Nonopioid analgesics; $\mathrm{n}(\%)$ & $296(98.7)$ & $298(99.3)$ & $298(99.0)$ & $449(99.1)$ & $443(98.9)$ \\
\hline NSAIDs; n (\%) & $285(95.0)$ & $288(96.0)$ & $286(95.0)$ & $453(95.8)$ & $425(94.9)$ \\
\hline Low-potent opioid analgesics; n (\%) & $207(69.0)$ & $208(69.3)$ & $210(69.8)$ & $311(68.7)$ & $314(70.1)$ \\
\hline Antidepressants; $\mathrm{n}(\%)$ & $206(64.3)$ & $203(67.7)$ & $191(63.5)$ & $301(66.4)$ & $299(66.7)$ \\
\hline Anticonvulsants; $\mathrm{n}(\%)$ & $113(37.7)$ & $109(36.3)$ & $112(37.2)$ & $178(39.3)$ & $156(34.8)$ \\
\hline Muscle relaxants; n (\%) & $193(64.3)$ & $180(60.0)$ & $196(65.1)$ & $292(64.5)$ & $277(6 \mid .8)$ \\
\hline Switch from WHO step I; n (\%) & $87(29.0)$ & $87(29.0)$ & $87(28.9)$ & $135(29.8)$ & $126(28.1)$ \\
\hline WHO step II; n (\%) & $207(69.0)$ & $208(69.3)$ & $210(69.8)$ & $311(68.7)$ & $314(70.1)$ \\
\hline Others; n (\%) & $6(2.0)$ & $5(1.7)$ & $4(1.3)$ & $7(I .5)$ & $8(1.8)$ \\
\hline MPSS I; n (\%) & $34(11.3)$ & $37(12.3)$ & $35(11.6)$ & $54(11.9)$ & $52(11.6)$ \\
\hline II; n (\%) & $153(51.0)$ & $151(50.3)$ & $15 \mid(50.2)$ & $238(52.5)$ & $217(48.4)$ \\
\hline III; n (\%) & $113(37.7)$ & $112(37.3)$ & $115(38.2)$ & $161(35.5)$ & $179(40.0)$ \\
\hline von Korff I; n (\%) & $23(7.7)$ & $25(8.3)$ & $22(7.3)$ & $31(6.8)$ & $39(8.7)$ \\
\hline $2 ; n(\%)$ & $105(35.0)$ & $110(36.7)$ & $108(35.9)$ & $179(39.5)$ & $144(32.1)$ \\
\hline 3; n (\%) & $12 \mid(40.3)$ & $113(37.7)$ & $118(39.2)$ & $166(36.6)$ & $186(4 \mid .5)$ \\
\hline $4 ; \mathrm{n}(\%)$ & $51(17.0)$ & $52(17.3)$ & $53(17.6)$ & $77(17.0)$ & $79(17.6)$ \\
\hline Neuropathic pain; n (\%) & $52(17.3)$ & $5 I(17.0)$ & $47(15.6)$ & $74(16.3)$ & $76(17.0)$ \\
\hline Tailored treatment target $\left(\mathrm{VAS}_{100}\right)$; mean $(\mathrm{SD})$ & $20.6(14.4)$ & $20.5(12.3)$ & $21.8(13.1)$ & $21.5(13.6)$ & $20.5(12.9)$ \\
\hline 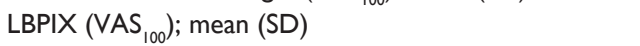 & $46.0(17.5)$ & $45.7(17.2)$ & $45.5(13.6)$ & $44.6(16.2)$ & $46.8(16.2)$ \\
\hline modified PDI $\left(\mathrm{NRS}_{70}\right)$; mean $(\mathrm{SD})$ & $41.7(13.5)$ & $42.3(13.0)$ & $42.4(13.0)$ & $41.8(12.9)$ & $42.5(13.4)$ \\
\hline QoL impairment by pain $\left(\mathrm{NRS}_{40}\right)$; mean (SD) & $17.2(5.9)$ & I7.I (5.7) & I7.| (5.6) & $17.5(5.8)$ & $16.8(5.7)$ \\
\hline $\mathrm{BFI}\left(\mathrm{VAS}_{100}\right) ;$ mean $(\mathrm{SD})$ & $19.6(19.6)$ & $19.9(19.4)$ & $19.9(19.3)$ & $20.3(19.9)$ & $19.3(19.0)$ \\
\hline Proportion with normal BFI ( $\left.\leq 28.8 \mathrm{~mm} \mathrm{VAS}_{100}\right) ; \mathrm{n}(\%)$ & $217(72.3)$ & $212(70.7)$ & $214(7 \mid .1)$ & $319(70.4)$ & $324(72.3)$ \\
\hline
\end{tabular}


A total of 37.7\% (340/901) patients presented with advanced pain "chronification" (stage III) according to the Mainz Pain Staging System (MPSS), ${ }^{39}$ and 56.4\% (508/901) suffered from a high disability with either moderate (grade III) (352/901 [39.1\%]) or severe (grade IV) (156/901 [17.3\%]) limitations according to the von Korff pain grading scale. ${ }^{40}$ Baseline pain intensity as well as all other pain-related patient measures were comparable among the treatment groups. The tailored treatment target was defined at baseline as $20.6 \pm 14.4$ for MOR, 20.5 \pm 12.3 for OXY, and 21.8 \pm 13.1 for OXN. Average LBP intensities, assessed on the basis of the LBP intensity index at baseline were $46.0 \pm 17.5 \mathrm{~mm}$ on the $\mathrm{VAS}_{100}$ for MOR, $45.7 \pm 17.2 \mathrm{~mm}$ on the $\mathrm{VAS}_{100}$ for OXY, and $45.5 \pm 13.6 \mathrm{~mm}$ on the $\mathrm{VAS}_{100}$ for OXN. Corresponding modified PDI and QoL impairment by pain scores for MOR, OXY, and OXN were $41.7 \pm 13.5,42.3 \pm 13.0$, and $42.4 \pm 13.0\left(\mathrm{NRS}_{70}\right)$, and 17.2 \pm 5.9 , $17.1 \pm 5.7$, and $17.1 \pm 5.6\left(\mathrm{NRS}_{40}\right)$, respectively. The proportion of patients presenting with a neuropathic LBP symptomatology was $17.3 \%(52 / 300)$ for MOR, $17.0 \%(51 / 300)$ for OXY, and 15.6\% (47/301) for OXN. The average BFI at baseline was $19.8 \pm 19.4$ (median 16, range $0-76$ ) $\mathrm{mm}$ on the VAS $_{100}$, with insignificant differences among the treatment and treatment allocation groups. The proportion of patients with normal BFI scores was 71.4\% (643/901).

\section{Opioid treatment}

With 28.7 \pm 11.8 (median 30, range 5-50) mg MEQ for MOR, 28.7 \pm 10.2 (median 30, range 10-60) mg MEQ for OXY, and $28.8 \pm 10.3$ (median 30, range 10-60) mg MEQ for OXN, the average initial starting doses were comparable among treatment and treatment allocation groups, as were the dose titration and the maintenance doses. At study end patients treated with MOR had received on average 103.8 \pm 39.3 (median 100, range 15-200) mg MEQ, while those with OXY received 106.6 \pm 37.4 (median 120, range 20-180) mg MEQ, and those with OXN received 112.9 \pm 34.2 (median 120, range 10-200) mg MEQ.

\section{Bowel function/opioid-induced constipation}

As expected, with the introduction of WHO step III opioids, the bowel function worsened significantly from baseline to end of study. The percentage of patients who maintained normal BFI scores (ie, $\leq 28.8$ ) throughout the 12-week treatment period was $54.5 \%(164 / 301)$ for OXN and hence significantly higher/better than that of OXY (32.8\% [98/300]) (OR: $2.47,95 \%$ CI: $1.77-3.44 ; P<0.001)$ or MOR $(29.7 \%$ [89/300]) (OR: 2.84, 95\% CI: 2.03-3.97; $P<0.001$ ) (Table 2). 
BFI scores increased from baseline to study end for MOR, from 19.6 \pm 19.6 to $53.6 \pm 33.1 \mathrm{~mm} \mathrm{VAS}_{100}(P<0.001)$, for OXY, from 19.9 \pm 19.4 to $48.2 \pm 32.3 \mathrm{~mm} \mathrm{VAS}_{100}(P<0.001)$, and for OXN, from $19.9 \pm 19.3$ to $30.0 \pm 26.2 \mathrm{~mm} \mathrm{VAS}_{100}$ $(P<0.001)$ (Figure 2). Between-group analyses showed significantly different BFI changes, with lowest absolute (relative) BFI increments at end of week 12 vs baseline for

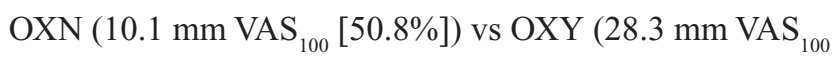
[142.2\%]) vs MOR (34.0 mm VAS $\left._{100}[173.5 \%]\right)$.

With 24.6\% (74/301), major relative BFI worsening (ie, $\geq 50 \%$ vs baseline) was found significantly less with OXN vs OXY (41.3\% [124/300]) (OR: 2.16, 95\% CI: 1.53-3.06; $P<0.001)$ and vs MOR (46.7\% [140/300]) (OR: 2.68, 95\% CI: 1.90-3.80; $P<0.001$ ) (Figure 3 and Table 3 ). Significantly more patients reported a clinically relevant absolute BFI increase ( $\left.\geq 12 \mathrm{~mm} \mathrm{VAS}_{100}\right)$ with $\operatorname{MOR}(72.3 \%$ [217/300]) (OR: 3.68, 95\% CI: 2.62-5.18; $P<0.001)$ and OXY (68.7\% [206/300]) (OR: 3.09, 95\% CI: 2.21-4.31; $P<0.001)$ compared with OXN (41.5\% [125/301]).

CSBMs decreased at least by one per week in $31 / 301$ patients with OXN (10.3\%) vs $127 / 300$ (42.3\%) for OXY (OR: 6.39, 95\% CI: 4.13-9.89; $P<0.001)$ vs 126/300 (42.0\%) for MOR (OR: 6.31, 95\% CI: 4.08-9.76; $P<0.001$ ). The average number of CSBMs per week dropped, for MOR from $4.4 \pm 1.7$ to $2.8 \pm 1.9(P<0.001)$, for OXY from $4.4 \pm 1.7$ to $2.8 \pm 2.0(P<0.001)$, and for OXN from $4.3 \pm 1.6$ to $3.9 \pm 1.8$ $(P<0.001)$. The percentage of patients with four or more CSBMs per week at study end was 62.1\% (187/301) for OXN vs 36.7\% (110/300) for OXY (OR: 2.83, 95\% CI: 2.04-3.94; $P<0.001)$ vs $32.7 \%$ (98/300) for MOR (OR: 3.38, 95\% CI: 2.42-4.73; $P<0.001)$.

The percentage of patients who used prescription laxatives prior to study participation was $23.0 \%$ both for MOR and OXY (69/300), and 22.6\% (68/301) for OXN, hence comparable between the treatment groups at baseline. The proportion of patients who were forced to use laxatives to prevent/treat OIC increased from baseline to study end, with MOR up to $57.3 \%$ (172/300), with OXY to 56.7 (170/300), and with OXN to $29.2 \%$ (88/301). Vice versa, the percentage of patients without any need for laxatives at baseline but who needed any at study end was significantly lower for OXN (8.6\% [20/233]) in comparison with OXY (43.7\% [101/231]) (OR: 8.27, 95\% CI: 4.89-14.02; $P<0.001)$ and MOR (44.6\% [103/231]) (OR: 8.60, 95\% CI: 5.06-14.51; $P<0.001)$.

With increasing constipation problems, the proportion of patients who started - in addition to their prescribed laxatives - nonprescription laxatives as well as dietary measures and/or exercise changes increased as well. The percentages

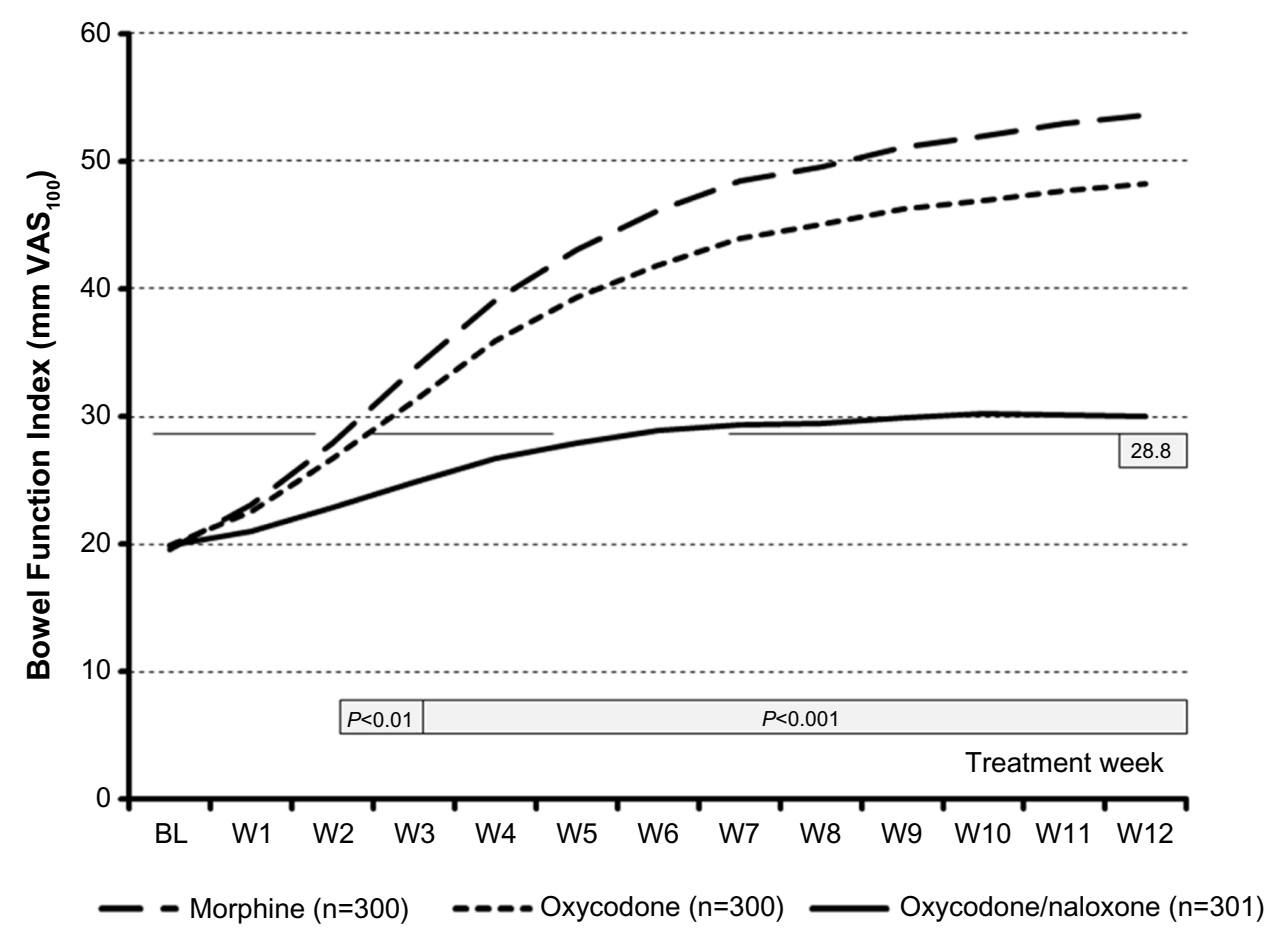

Figure 2 Change in mean BFI score during the course of the I2-week study.

Notes: BFI changed significantly for all three treatment groups vs baseline but significantly less for oxycodone/naloxone vs oxycodone vs morphine. The horizontal line marked with "28.8" indicates the upper normal reference range of the BFI; the horizontal bars indicate significance level with respect to treatment comparisons between oxycodone/naloxone vs oxycodone and morphine. The VAS ${ }_{100}$ was scored as $0=$ no bowel dysfunction and $100=$ worst bowel dysfunction conceivable. Abbreviations: BFI, Bowel Function Index; BL, baseline; $\mathrm{VAS}_{100}$, $100 \mathrm{~mm}$ horizontal visual analog scale; $\mathrm{W}$, treatment week. 


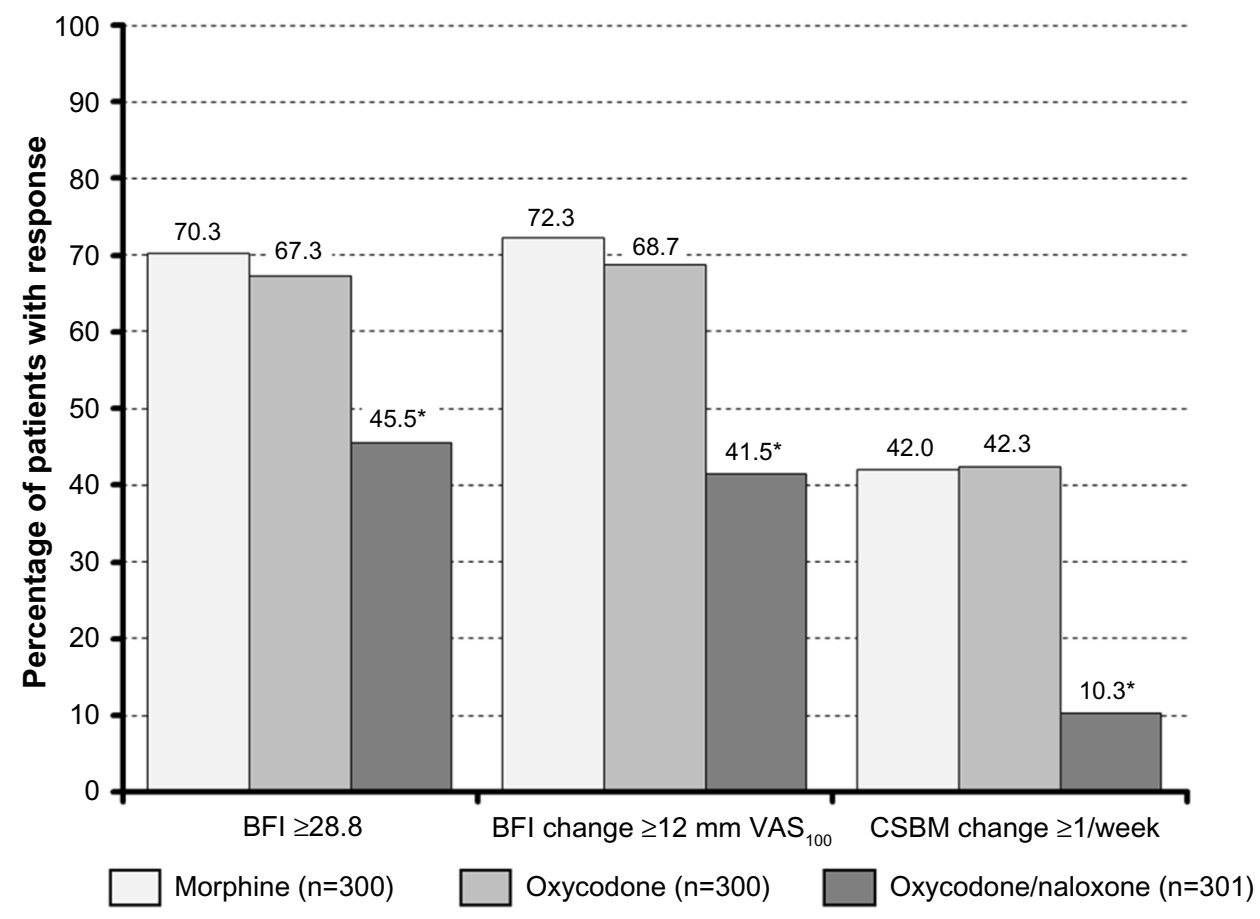

Figure 3 Proportion of patients who recorded a Bowel Function Index score above the normal range ( $\geq 28.8$ ) (left), a significant worsening vs baseline ( $\geq 12$ mm) (middle), and a CSBM $\geq$ I decrease vs baseline (right) at the end of a I2-week treatment with morphine (light grey), oxycodone (grey), and oxycodone/naloxone (dark grey). Note: *Significant difference $(P<0.001)$ for oxycodone/naloxone vs morphine and vs oxycodone.

Abbreviations: BFI, Bowel Function Index; CSBM, complete spontaneous bowel movement; $\mathrm{VAS}_{100}$, 100 mm horizontal visual analog scale.

of patients who took none of these measures at baseline and who started to use any due to side effects of the opioid treatment increased with OXN significantly less (27.1\% [58/214]) than with OXY (83.2\% [168/202]) (OR: 13.29, 95\% CI: 8.26-21.40; $P<0.001)$ or MOR (89.4\% [178/199]) (OR: 22.80, 95\% CI: $13.30-39.26 ; P<0.001)$.

\section{Efficacy analyses}

Opioid treatment was followed by a significant relief in pain and pain-related complaints for all three treatment groups, however, with superior effects for $\mathrm{OXN}$ in comparison with OXY and MOR (Figure 4). LBP intensity index decreased with OXN, OXY, and MOR, from 45.5 $\pm 13.6,45.7 \pm 17.2$, and $46.0 \pm 17.5 \mathrm{~mm} \mathrm{VAS}_{100}$, respectively, at baseline to $17.8 \pm 16.9,24.0 \pm 19.8$, and $24.8 \pm 19.4 \mathrm{~mm} \mathrm{VAS}_{100}$, respectively, at study end. Corresponding absolute (relative) (ie, $\left.m m \operatorname{VAS}_{100}[\%]\right)$ changes at study end vs baseline were for OXN, with $-27.7 \pm 15.9(-62.5 \pm 32.7)$, significantly greater than those reported for OXY $(-21.7 \pm 18.7[-48.1 \pm 39.6])$ $(P<0.001)$ or MOR $(-21.1 \pm 18.0[-45.2 \pm 42.4])(P<0.001)$. The end of study percentage of patients who presented with at least $50 \%$ pain relief vs baseline was significantly higher for OXN (69.4\% [209/301]) than for OXY (59.3\% [178/300]) (OR: $1.56,95 \%$ CI: $1.11-2.18 ; P<0.001)$ or MOR $(51.3 \%$ [154/300]) (OR: 2.15, 95\% CI: 1.54-3.01; $P<0.001)$.
In parallel, pain-related restrictions of daily life activities and QoL improved as well. The percentages of patients who finally reported $\mathrm{a} \geq 50 \%$ improvement in pain-related disabilities with respect to daily life activities, assessed via modified PDI, were 59.5\% (179/301) for OXN vs 48.0\% (144/300) for OXY (OR: $1.59,95 \%$ CI: $1.15-2.20 ; P<0.001)$ vs $44.3 \%$ (133/300) for MOR (OR: 1.84, 95\% CI: 1.33-2.55; $P<0.001$ ). The proportion of patients who presented with a $\geq 50 \% \mathrm{QoL}$ improvement as assessed via QoL impairment by pain was $72.8 \%$ (219/301) for OXN vs 46.0\% (138/300) for OXY (OR: $3.14,95 \%$ CI: $2.23-4.41 ; P<0.001)$ vs $40.0 \%(120 / 300)$ for MOR (OR: 4.01, 95\% CI: 2.84-5.65; $P<0.001$ ).

\section{Treatment satisfaction}

Overall, physician satisfaction with the WHO step III opioids was good. On a patient basis, physicians recorded for OXN a significantly higher treatment satisfaction vs baseline $(90.7 \%$ [273/301]) in comparison with OXY $(64.7 \%$ [194/300]) (OR: 5.33, 95\% CI: 3.38-8.40; $P<0.001)$ and MOR (59.3\% [178/300]) (OR: 6.68, 95\% CI: 4.25-10.50; $P<0.001)$. Patient condition improved "very much" or "much" vs prior treatments in $88.0 \%$ (265/301) with OXN vs $50.3 \%$ (151/300) with OXY (OR: 7.26, 95\% CI: 4.80-11.00; $P<0.001)$ vs $47.3 \%(142 / 300)$ with MOR (OR: $8.19,95 \%$ CI: 5.41-12.41; $P<0.001)$. 


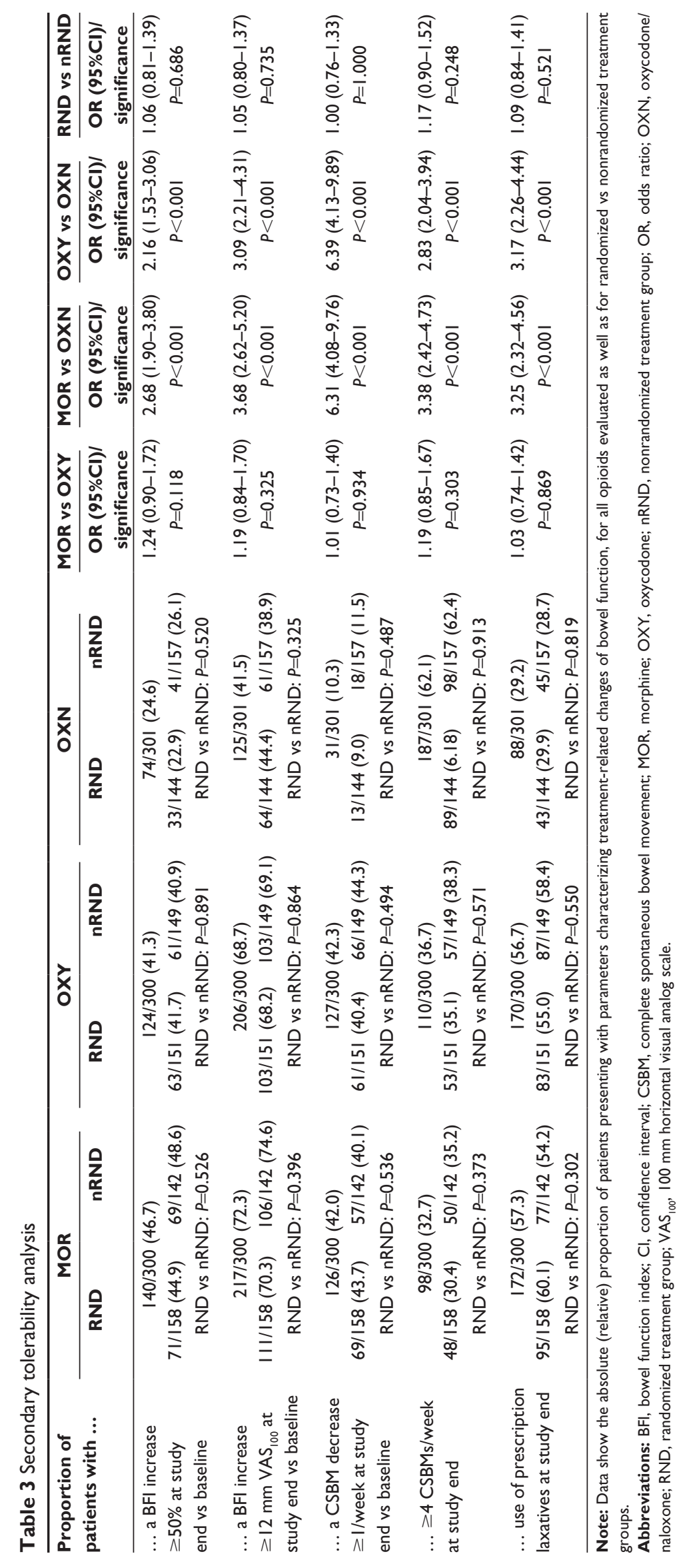




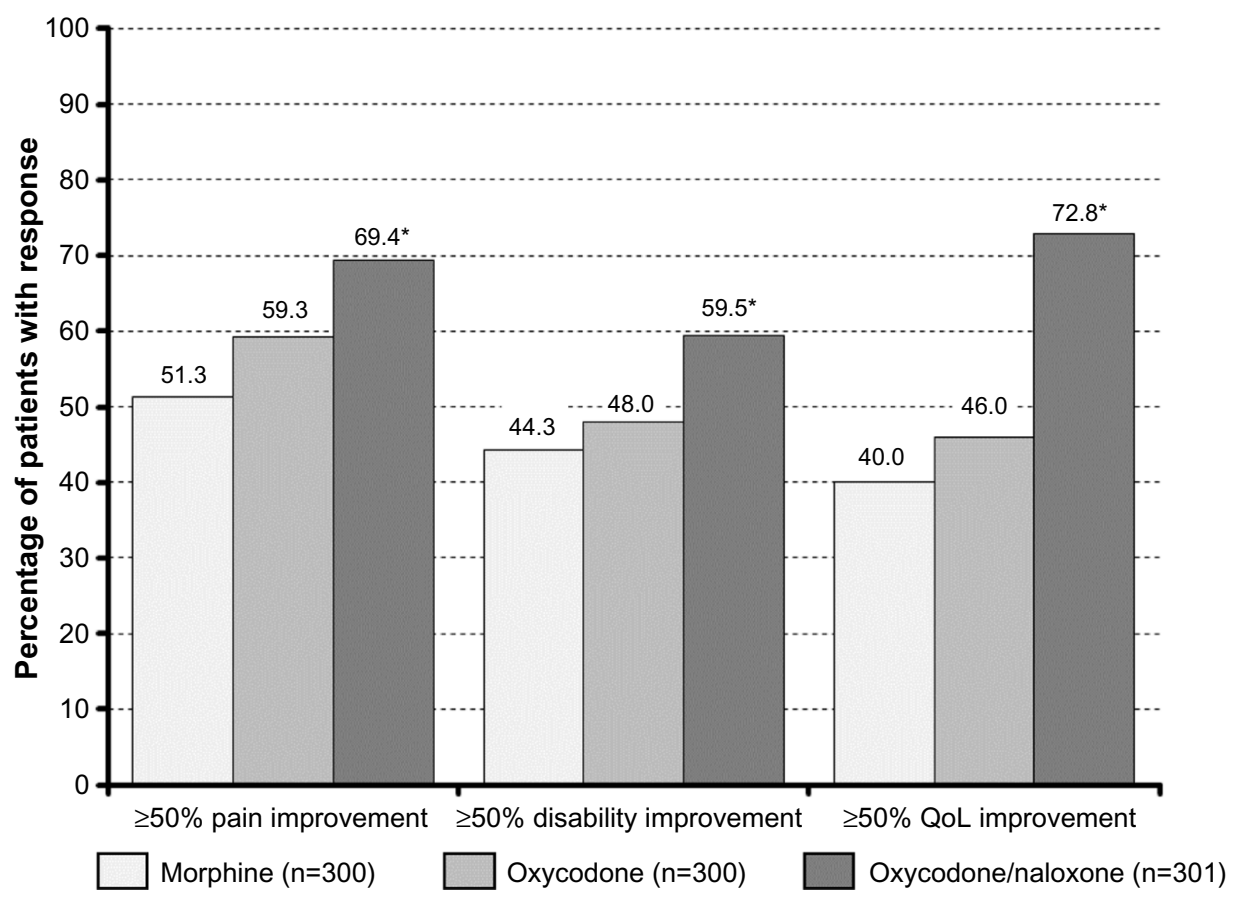

Figure 4 Proportion of patients who recorded a $\geq 50 \%$ improvement (vs baseline) with respect to pain intensity (left), pain-related disabilities in daily life (middle), and quality of life (right) at the end of a I2-week treatment with morphine (light grey), oxycodone (grey), and oxycodone/naloxone (dark grey).

Note: *Significant difference $(P<0.001)$ for oxycodone/naloxone vs morphine and vs oxycodone.

Abbreviation: QoL, quality of life.

\section{Safety evaluation}

As shown in Figures 5 and 6, 13.6\% (41/301) of OXN patients reported at least one TEAE in comparison with $26.7 \%$ (80/300) for OXY (OR: 2.31, 95\% CI: 1.51-3.50; $P<0.001)$ and $27.7 \%(83 / 300)$ for MOR (OR: $2.43,95 \%$ CI: $1.60-3.67 ; P<0.001)$. Two or more TEAEs were reported with OXN by $8.3 \%(25 / 301)$, with OXY by $13.7 \%(41 / 300)$, and with MOR by $14.7 \%$ (44/300) of patients. TEAE-related treatment discontinuations were seen in 7.3\% (22/301) of patients treated with OXN vs $24.7 \%$ (74/300) with OXY (OR: 4.15, 95\% CI: $2.50-6.90 ; P<0.001)$ vs $25.3 \%$ (76/300) with MOR (OR: 4.30, 95\% CI: 2.59-7.14; $P<0.001$ ). Overall, 359 TEAEs were observed throughout the conduct of this study, 78 in relation with OXN, 134 with OXY, and 147 with MOR. A detailed TEAE analysis (Table 4) revealed that among the 177 events (49.3\%), the majority of those TEAEs affected the GI tract, followed by 141 events (39.3\%) affecting the central nervous system (CNS), 22 events (6.1\%) affecting metabolism, 18 events (5.0\%) affecting the skin, and one event $(0.3 \%)$ classified as psychiatric. Constipation as a reportable TEAE was the most frequently documented drug-related adverse event, noted with OXN, OXY, and MOR, respectively, in $5.0 \%, 12.7 \%$, and $12.7 \%$, followed by nausea $(4.3 \%, 8.7 \%$, and $11.0 \%)$ and somnolence $(6.3 \%$, $9.3 \%$, and $9.7 \%)$. With $17.0 \%(61 / 359)$ and $51.8 \%(186 / 359)$, respectively, most TEAEs were classified as mild or moderate intense, and in $31.2 \%(112 / 359)$ these were severe. In all cases, TEAEs recovered completely, either without any counter measures (7.0\% [25/359]), after treatment discontinuation $(88.6 \%$ [318/359]), or with supportive drug treatment $(4.5 \%$ [16/359]). Safety analyses performed for randomized vs nonrandomized patients revealed only minor and insignificant differences between treatment allocation groups.

\section{Discussion}

OIC, the most prevalent and persistent side effect of long-term treatment with WHO step III opioids, develops gradually and frequently despite prophylactic and therapeutic countermeasures. This was a post hoc analysis of so far unpublished data derived from a 12-week, real-life study designed to evaluate the GI tolerability of three different oral PR WHO step III opioids in a typical clinical practice setting. The findings were that treatment with OXN was characterized by a significantly higher proportion of patients who were able to maintain normal bowel function in comparison with OXY and MOR, as assessed via BFI and CSBM analyses. Reported differences were not related to differences in dosing (as daily morphine equivalents were comparable among treatment groups) or to a different use of laxatives or related countermeasures between the treatment 


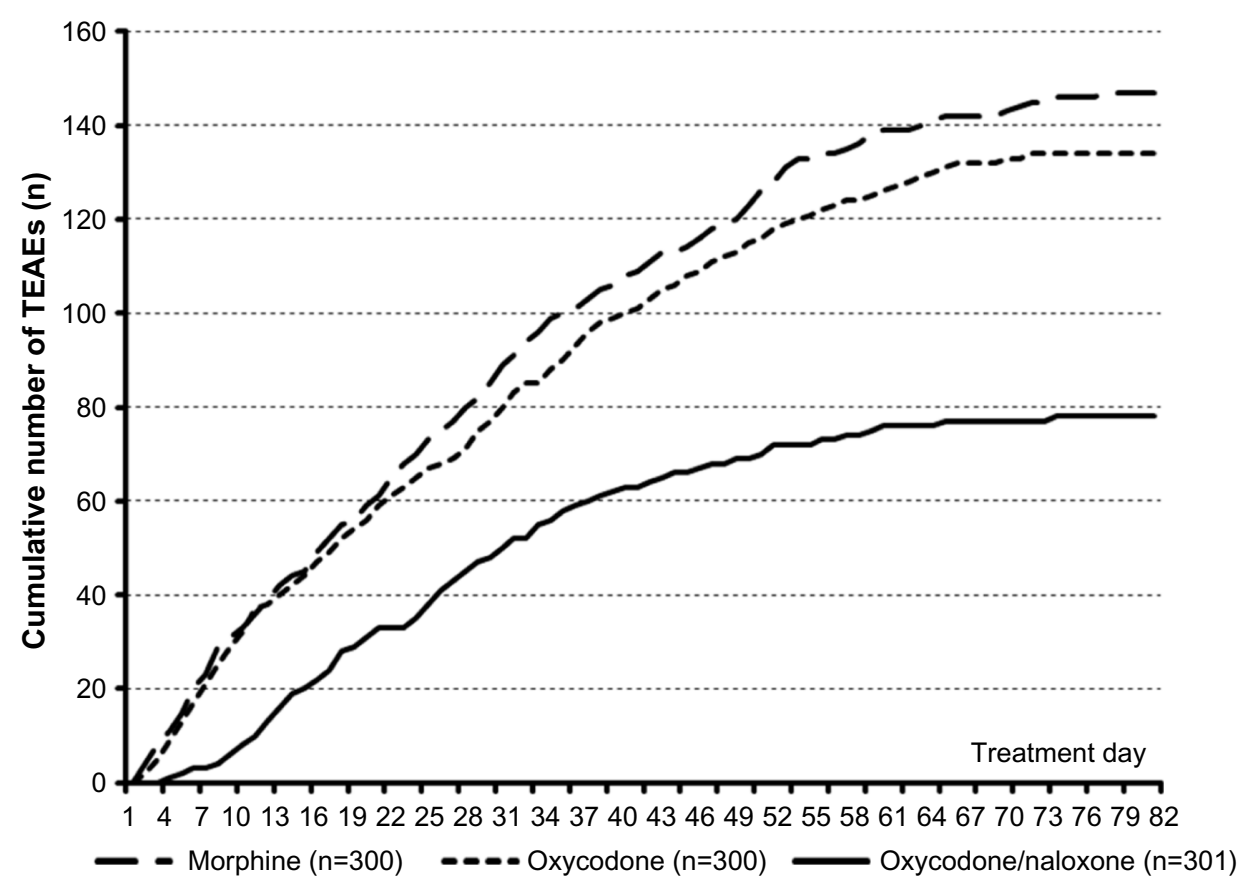

Figure 5 Distribution of time to onset of TEAEs reported for morphine (dashed line), oxycodone (dotted line), and oxycodone/naloxone (solid line) during a I2-week treatment period.

Abbreviation: TEAE, treatment-emergent adverse event.

groups (as the proportion of patients receiving these agents by prescription or over the counter were significantly lower for OXN compared with OXY and MOR), supporting, not only the rationale that $\mathrm{OXN}$ counteracts OIC via naloxone through mechanisms specifically addressing the underlying processes but also, highlighting the limited efficacy of laxative regimens in OIC.

The importance of OIC (respective its prevention by adequate countermeasures) for patients suffering from chronic pain is highlighted by the reported differences for MOR,

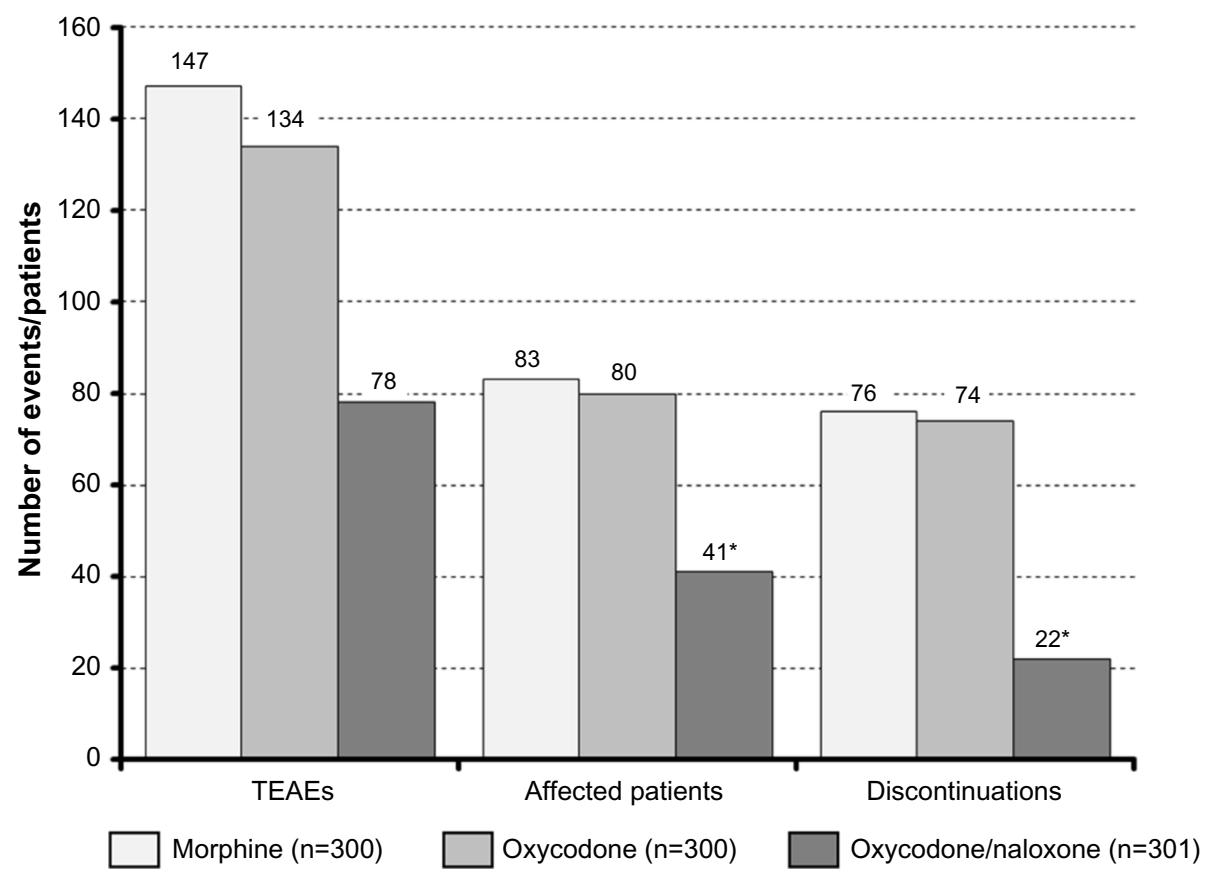

Figure 6 Number of TEAEs (left), patients affected by TEAEs (middle), and patients forced to discontinue treatment due to a TEAE (right), recorded during a I2-week treatment with morphine (light grey), oxycodone (grey), and oxycodone/naloxone (dark grey).

Note: *Significant difference $(P<0.001)$ for oxycodone/naloxone vs morphine and vs oxycodone.

Abbreviation: TEAEs, treatment-emergent adverse events. 
Table 4 Overall TEAE experience

\begin{tabular}{|c|c|c|c|c|c|}
\hline & MOR $(n=300)$ & OXY $(n=300)$ & OXN (n=30I) & RND ( $n=453)$ & $\begin{array}{l}n R N D \\
(n=448)\end{array}$ \\
\hline Number of TEAEs & 147 & 134 & 78 & 189 & 170 \\
\hline Number of serious TEAEs & - & - & - & - & - \\
\hline Subjects with TEAEs & $83(27.7)$ & $80(26.7)$ & $4 I(13.6)$ & $102(22.5)$ & $102(22.8)$ \\
\hline Subjects with $\geq 2$ TEAEs & $45(15.0)$ & $4 \mid(13.7)$ & $25(8.3)$ & $59(13.0)$ & $52(11.6)$ \\
\hline \multicolumn{6}{|l|}{ Most common TEAEs } \\
\hline Constipation & $38(12.7)$ & $38(12.7)$ & I5 (5.0) & $55(12.1)$ & $36(8.0)$ \\
\hline Nausea & $33(11.0)$ & $26(8.7)$ & $13(4.3)$ & $35(7.7)$ & $37(8.3)$ \\
\hline Somnolence & $29(9.7)$ & $28(9.3)$ & $19(6.3)$ & $40(8.8)$ & $36(8.0)$ \\
\hline Dizziness & $15(5.0)$ & $14(4.7)$ & $9(3.0)$ & $15(3.3)$ & $23(5.1)$ \\
\hline Vomiting & $10(3.3)$ & $7(2.3)$ & $5(1.7)$ & $13(2.9)$ & $9(2.0)$ \\
\hline Sleep problems & $6(2.0)$ & $6(2.0)$ & $5(1.7)$ & II (2.4) & $6(1.3)$ \\
\hline Sweating & $4(1.3)$ & $3(1.0)$ & $3(1.0)$ & $5(1.1)$ & $5(1.1)$ \\
\hline Headache & $2(0.7)$ & $3(1.0)$ & $3(1.0)$ & $4(0.9)$ & $4(0.9)$ \\
\hline Abdominal pain & $4(1.3)$ & $3(1.0)$ & $\mathrm{I}(0.3)$ & $4(0.9)$ & $4(0.9)$ \\
\hline Others & $6(2.0)$ & $6(2.0)$ & $5(1.7)$ & $7(1.5)$ & $10(2.2)$ \\
\hline \multicolumn{6}{|l|}{ Affected organ classes } \\
\hline Gastrointestinal system & $77(25.7)$ & $69(23.0)$ & $31(10.3)$ & $96(21.2)$ & $81(18.1)$ \\
\hline Nervous system & $53(17.7)$ & $52(17.3)$ & $36(12.0)$ & $72(15.9)$ & $69(15.4)$ \\
\hline Metabolic system & $10(3.3)$ & $7(2.3)$ & $5(1.7)$ & II (2.4) & II (2.5) \\
\hline Skin & $7(2.3)$ & $6(2.0)$ & $5(1.7)$ & $9(2.0)$ & $9(2.0)$ \\
\hline Psychiatric system & $-(-)$ & $-(-)$ & $\mathrm{I}(0.3)$ & $\mathrm{I}(0.2)$ & $-(-)$ \\
\hline \multicolumn{6}{|l|}{ Intensity } \\
\hline Mild & $24(16.3)$ & $21(15.7)$ & $16(20.5)$ & $32(7.1)$ & $29(6.5)$ \\
\hline Moderate & $77(52.4)$ & 7II (53.0) & 38 (48.7) & $105(23.2)$ & $81(18.1)$ \\
\hline Severe & $46(31.3)$ & $42(3 \mid .3)$ & $24(30.8)$ & $52(I I .5)$ & $60(13.4)$ \\
\hline \multicolumn{6}{|l|}{ Counter measures } \\
\hline None & $8(5.4)$ & $2(1.5)$ & 15 (19.2) & $6(1.3)$ & $19(4.2)$ \\
\hline Pharmacotherapy & $4(2.7)$ & $4(3.0)$ & $8(10.3)$ & $9(2.0)$ & $7(1.6)$ \\
\hline Treatment discontinuation (TEAEs) & $135(91.8)$ & $128(95.5)$ & $55(70.5)$ & $174(38.4)$ & $144(32.1)$ \\
\hline Treatment discontinuation (patients) & $75(25.0)$ & $74(24.7)$ & $22(7.3)$ & $90(19.9)$ & $81(8.1)$ \\
\hline $\begin{array}{l}\text { Treatment discontinuations for } \\
\text { any reason (patients) }\end{array}$ & $129(43.0)$ & $115(38.3)$ & $76(25.2)$ & $167(36.9)$ & $153(34.2)$ \\
\hline
\end{tabular}

Note: Data is presented as $n(\%)$.

Abbreviations: MOR, morphine; n, number of patients; nRND, nonrandomized patients; OXN, oxycodone/naloxone; OXY, oxycodone; RND, randomized patients; TEAEs, treatment emergent adverse events.

OXY, and OXN with respect to pain relief as well as overall treatment satisfaction. As reported, treatment with OXN was associated, not only with significantly less bowel dysfunction and a superior tolerability in comparison with OXY and MOR but also, with a biometrically and clinically relevant superior analgesic efficacy, which was associated with significantly superior improvements of pain-related disabilities in daily life as well as QoL. Consequently, the proportion of patients whose overall condition improved with the opioid treatment was significantly superior for OXN vs OXY and MOR, and the corresponding ORs of 7.3 and 8.2 underline the clinical relevance of the combined opioid agonist/antagonist combination and its importance for patients.

Attempts to explain the origin of these efficacy differences focus primarily on OIC-related issues, such as the reduction of OIC-related painful symptoms (eg, bloating/ flatulence, abdominal pain/colic, painful defecation, etc) by the naloxone compound; this in turn, vice versa, may have led to an overall reduced burden of pain and hence, to lower pain intensity reported by patients treated with OXN vs OXY and/or MOR. In addition, the naloxone-related improvement of bowel function might have been followed by an improved GI resorption of the agonist compound of OXN and as such, by a higher systemic bioavailability, which subsequently may have resulted in a stronger activation of opioid-receptors within the nervous system. Alternative explanations relate to observations that naloxone per se seems to exhibit analgesic effects via opioid receptor-independent pathways within the CNS, which - if applied in ultralow dosages $(\sim 1-2 \mu \mathrm{g} / \mathrm{kg}$ body weight) and during chronic exposure - might add to the opioid receptor-mediated activities of opioid analgesics. ${ }^{41-46}$ This hypothesis is contradictory to usual beliefs of naloxone as a potent opioid receptor antagonist; however, the effects of naloxone on the nociceptive system are somewhat more complex than they first appeared. The administration of the naloxone compound within OXN differs pharmacologically 
from conventional naloxone (eg, given intravenously as immediate release preparation to antagonize opioid-related side effects or overdose) predominantly by its a) use as an oral tablet developed for enteral absorption, b) slow absorption caused by a special PR formulation, c) predominantly preheated (local) interaction with opioid receptors in the submucosal and mesenteric plexuses of the gut, and d) very low (1\%-2\%) systemic bioavailability, due to an extensive first pass metabolism by the liver. All in all, these factors lead to the occurrence of very low but continuously available amounts of naloxone in the bloodstream (in our study $0.610 \pm 0.223$ [median 0.605, range $0.057-1.225$ ] $\mu \mathrm{g} / \mathrm{kg} / \mathrm{hr}$ ), which were exactly within the range previously defined as prerequisite to exhibit analgesic effects. ${ }^{41,46}$ Additionally, this hypothesis is supported by the fact that in our study, OXN was also more effective (vs OXY vs MOR) in those patients, who presented without any opioid-related bowel dysfunction during the course of the 12-week treatment period.

As shown by those $9.3 \%$ (28/301) of OXN-treated patients who experienced a CSBM decrease $\geq 1$ /week despite additional laxatives, naloxone was not able to prevent OIC. Despite the fact that this proportion of patients is significantly less that was seen with OXY (33.3\% [100/300]) (OR: 4.88, 95\% CI: 3.09-7.70; $P<0.001)$ or MOR $(33.0 \%$ [99/300]) (OR: 4.80, 95\% CI: 3.04-7.59; $P<0.001$ ), this is more than expected if OIC is assumed to be purely peripherally mediated, raising a few questions about the underlying pathophysiology. Usually, OIC is seen as a consequence of opioid interaction with $\mu$-opioid receptors located within the neuronal systems of the plexus myentericus and plexus submucosus of the GI tract, followed by reduced GI motility and a reduced secretion of digestive enzymes, increased fluid absorption, and increased sphincter tone. However, experimental studies were able to verify clinically relevant, centrally mediated opioid effects on the GI tract after intracerebroventricular administration of morphine as well, which could be reversed either by CNS coadministration of naloxone or vagotomy, ${ }^{47-49}$ supporting the hypothesis that peripheral as well as central opioid effects are responsible for OIC. ${ }^{50,51}$ Further, if at all, indirect evidence for this hypothesis can be taken from the fact that methylnaltrexone - a purely peripherally acting $\mu$-opioid receptor antagonist - improves OIC-related GI dysfunction only in $50 \%-60 \%$ of patients, providing some indication of the relevance of peripherally mediated mechanisms for OIC. ${ }^{52,53}$

To our surprise, OIC was obviously not an inevitable consequence of opioid treatment, as not all patients treated with OXY or MOR experienced a significant increase in related parameters, such as the BFI, or reported relevant CSBM changes. Overall, 31.2\% (187/600) patients treated either with MOR or OXY presented with "normal" BFI scores at study end, 29.5\% (177/600) experienced only minor and neither statistically significant nor clinically relevant BFI changes in response to these opioids, and 16.0\% (96/600) did so without any prescribed laxatives or other documented countermeasures. Even though corresponding percentages for OXN were, with 54.5\% (164/301), 58.5\% (176/301), and 47.5\% (143/301) (OR: 2.64, 3.37, and 4.75, respectively; $P<0.001$ for each comparison), significantly greater, these data as well as those for CNS effects described earlier clearly show that the level of our understanding of the pathophysiological mechanisms underlying OIC in pain patients treated with WHO step III opioids is incomplete.

Irrespective of this, treatment with OXN induced significantly less OIC and OIC-related health problems than did treatment with OXY and MOR. Assuming that those patients who presented at baseline with BFI scores $\geq 28.8$ suffered from nonopioid-related constipation $(27.7 \%$ in the MOR group, $29.3 \%$ for OXY and $28.9 \%$ for OXN), only the differences to the corresponding percentages at study end or the percentages of patients with normal BFI scores at baseline, who presented with abnormal BFI scores at study end could be taken as truly WHO step III related and by such preventable by an opioid receptor antagonist like naloxone. Following this hypothesis, the percentage of patients who developed OIC beyond baseline was for OXN (23.4\% [50/214]) significantly lower than that seen for OXY (53.8\% [114/212]) (OR: 3.82, 95\% CI: 2.52-5.79; $P<0.001)$ and MOR $(59.0 \%$ [128/217]) (OR: 4.72, 95\% CI: 3.11-7.15; $P<0.001)$. This four- to fivefold decreased risk for OIC highlights - especially in combination with the significantly lower use of laxatives and related measures - the superior GI tolerability profile of OXN in comparison with OXY and MOR, and its practical advantage for daily life treatments.

Overall, treatment with any of the three WHO step III opioids was safe. None of the study patients died nor showed any serious or unexpected TEAEs or persistent adverse effects after treatment discontinuation. The drug treatments differed significantly with respect to the number of patients affected by TEAEs, the overall number of TEAEs observed, and the percentage of patients forced to discontinue opioid treatment in favor of OXN vs OXY and MOR. The spectrum of TEAEs reported was comparable with those mentioned in the current Summary of Product Characteristics (SPCs). The number of OXN patients with TEAEs was close to those reported in previous studies, ${ }^{20-26}$ however, discontinuation rates were 
somewhat higher, which may reflect minor differences with respect to study design and/or conduct of study.

The patients who received one of the opioids evaluated in the original study by chance (ie, due to a randomization process) or by preference of their physician (ie, nonrandomized) were comparable with respect to their demographic as well as baseline characteristics. Obviously, the data set obtained and evaluated within the original study was insufficient to explain the possible reasons that physicians chose to follow or to reject the randomized opioid selection. In addition, treatment allocation effects on tolerability, efficacy, and safety were only minor, and as well, were clinically insignificant. The main explanation for this might be the open-label design that allowed physicians and patients to tailor opioid treatments to the individual needs of participating patients and to address requested effects as well as untoward treatment reactions on an as-needed basis.

\section{Study limitations}

This study has certain limitations. PROBE-designed studies such as the one underlying the present post hoc analysis suffer several limitations in comparison with RCTs. ${ }^{54}$ Most of these limitations are inherent to the open-label design, which comes along with a significant risk of bias. That is, patients or investigators may add concomitant treatments to address lack of efficacy, to improve tolerability, or to manage symptoms or risk based on their knowledge and beliefs of treatment allocation. However, although opioid medications were open label, the determination of endpoints in the original study was blinded, and the use of combined endpoints addressing safety, tolerability, and efficacy parameters (which were, as such, not reported to study participants) guaranteed valid results, invaluable for real-life treatment decisions. The results of the combined evaluation of randomized and nonrandomized patients expands current knowledge on differential opioid effects with respect to OIC and related health problems. Between-group comparisons revealed only minor and neither biometrically nor clinically relevant differences with respect to any parameters evaluated.

\section{Conclusion}

OIC is the most frequently reported adverse event experienced by patients receiving long-term opioid therapy, and interferes significantly with opioid treatment effects, such as pain relief, and improvement in functionality and/or QoL. This post hoc analysis of data from a PROBE study provides valuable GI safety, tolerability, and efficacy data for MOR, OXY, and OXN, three WHO step III opioids frequently used to treat patients with elsewhere refractory LBP. Patientreported data revealed significant differences between these opioid analgesics with respect to the development of OIC and the occurrence of opioid-related adverse events, with superior effects of OXN vs OXY and MOR. Additionally, patients reported superior analgesic effects for OXN with respect to pain relief, as well as related improvements for daily life activities and QoL. Overall, this data provides evidence that the fixed agonist/antagonist combination of OXN is a safe, better tolerated, and more effective alternative to conventional opioid agonists, such as OXY and MOR.

\section{Author contributions}

All authors contributed toward data analysis, drafting and revising the paper and agree to be accountable for all aspects of the work.

\section{Acknowledgments}

Data of the PROBE study were presented at the World Pain Congress of the International Association for the Study of Pain, October 6-11, 2014, Buenos Aires, Argentina. Data of this post hoc analysis will be presented at the Ninth Congress of the European Pain Federation, September 2-5, 2015, Vienna, Austria.

\section{Disclosure}

The concept for the original PROBE study as well as this post hoc analysis was developed by the Institute for Neurological Sciences on behalf of the German Pain Association (Deutsche Gesellschaft für Schmerzmedizin) and the German Pain League (Deutsche Schmerzliga). The original study was realized by an independent contract research organization (CRO) and partly $(<49 \%)$ sponsored by an unrestricted scientific grant from Mundipharma, Germany. Neither the study sponsor, nor any of its employees exerted any influence on the conduct of the study, or on analyses, interpretation, or publication of the results. The current post hoc analysis was done independently of any financial and/or intellectual influence by the authors. MAU and GHHM-S are physicians with no significant/relevant financial or other relationship to the sponsor, except for minor reimbursements for occasional lectures or consultations.

The authors report no other conflicts of interest in this work.

\section{References}

1. Breivik H, Collett B, Ventafridda V, Cohen R, Gallacher D. Survey of chronic pain in Europe: prevalence, impact on daily life, and treatment. Eur J Pain. 2006;10(4):287-333. 
2. Reid KJ, Harker J, Bala MM, et al. Epidemiology of chronic non-cancer pain in Europe: narrative review of prevalence, pain treatments and pain impact. Curr Med Res Opin. 2011;27(2):449-462.

3. Sng BL, Schug SA. The role of opioids in managing chronic non-cancer pain. Ann Acad Med Singapore. 2009;38(11):960-966.

4. Wiffen PJ. Evidence-based pain management and palliative care in issue one for 2005 of The Cochrane Library. J Pain Palliat Care Pharmacother. 2005;19(3):65-68.

5. Caraceni A, Hanks G, Kaasa S, et al; European Palliative Care Research Collaborative (EPCRC); European Association for Palliative Care (EAPC). Use of opioid analgesics in the treatment of cancer pain: evidence-based recommendations from the EAPC. Lancet Oncol. 2012;13(2):e58-e68.

6. Ahmedzai SH, Nauck F, Bar-Sela G, Bosse B, Leyendecker P, Hopp M. A randomized, double-blind, active-controlled, doubledummy, parallel-group study to determine the safety and efficacy of oxycodone/naloxone prolonged-release tablets in patients with moderate/severe, chronic cancer pain. Palliat Med. 2012;26(1):50-60.

7. Chou R, Huffman LH; American Pain Society; American College of Physicians. Medications for acute and chronic low back pain: a review of the evidence for an American Pain Society/American College of Physicians clinical practice guideline. Ann Intern Med. 2007;147(7): 505-514.

8. Kahan M, Mailis-Gagnon A, Wilson L, Srivastava A; National Opioid Use Guideline Group. Canadian guideline for safe and effective use of opioids for chronic noncancer pain: clinical summary for family physicians. Part 1: general population. Can Fam Physician. 2011;57(11): 1257-66.

9. Häuser W, Bock F, Engeser P, Tölle T, Willweber-Strumpfe A, Petzke F. Long-term opioid use in non-cancer pain. Dtsch Arztebl Int. 2014;111(43):732-740.

10. Pappagallo M. Incidence, prevalence, and management of opioid bowel dysfunction. Am J Surg. 2001;182:11S-18S.

11. Coluzzi F, Pappagallo M; National Initiative on Pain Control. Opioid therapy for chronic noncancer pain: practice guidelines for initiation and maintenance of therapy. Minerva Anestesiol. 2005;71(7-8):425-433.

12. Bell TJ, Panchal SJ, Miaskowski C, Bolge SC, Milanova T, Williamson R. The prevalence, severity, and impact of opioid-induced bowel dysfunction: results of a US and European Patient Survey (PROBE 1). Pain Med. 2009;10(1):35-42.

13. Kurz A, Sessler DI. Opioid-induced bowel dysfunction: pathophysiology and potential new therapies. Drugs. 2003;63(7):649-671.

14. Becker G, Galandi D, Blum HE. Peripherally acting opioid antagonists in the treatment of opiate-related constipation: a systematic review. J Pain Symptom Manage. 2007;34(5):547-565.

15. Panchal SJ, Müller-Schwefe P, Wurzelmann JI. Opioid-induced bowel dysfunction: prevalence, pathophysiology and burden. Int J Clin Pract. 2007;61(7):1181-1187.

16. Odegard PS, Burke C. Managements of opioid induced constipation in elderly patients. Consultant Pharmacist. 1996;11:17-22.

17. Leppert $W$.The role of opioid receptor antagonists in the treatment of opioidinduced constipation: a review. Adv Ther. 2010;27(10):714-730.

18. Mercadante S, Giarratano A. Combined oral prolonged-release oxycodone and naloxone in chronic pain management. Expert Opin Investig Drugs. 2013;22(1):161-166.

19. Meissner W, Leyendecker P, Mueller-Lissner S, et al. A randomised controlled trial with prolonged-release oral oxycodone and naloxone to prevent and reverse opioid-induced constipation. Eur J Pain. 2009; 13(1):56-64.

20. Löwenstein O, Leyendecker P, Hopp M, et al. Combined prolonged-release oxycodone and naloxone improves bowel function in patients receiving opioids for moderate-to-severe non-malignant chronic pain: a randomised controlled trial. Expert Opin Pharmacother. 2009;10(4):531-543.

21. Löwenstein O, Leyendecker P, Lux EA, et al. Efficacy and safety of combined prolonged-release oxycodone and naloxone in the management of moderate/severe chronic non-malignant pain: results of a prospectively designed pooled analysis of two randomised, double-blind clinical trials. BMC Clin Pharmacol. 2010;10:12.
22. Vondrackova D, Leyendecker P, Meissner W, et al. Analgesic efficacy and safety of oxycodone in combination with naloxone as prolonged release tablets in patients with moderate to severe chronic pain. $J$ Pain. 2008;9(12):1144-1154.

23. Sandner-Kiesling A, Leyendecker P, Hopp M, et al. Long-term efficacy and safety of combined prolonged-release oxycodone and naloxone in the management of non-cancer chronic pain. Int $J$ Clin Pract. 2010;64(6):763-774.

24. Ahmedzai SH, Leppert W, Janecki M, et al. Long-term safety and efficacy of oxycodone/naloxone prolonged-release tablets in patients with moderate-to-severe chronic cancer pain. Support Care Cancer. 2015;23(3):823-830.

25. Blagden M, Hafer J, Duerr H, Hopp M, Bosse B. Long-term evaluation of combined prolonged-release oxycodone and naloxone in patients with moderate-to-severe chronic pain: pooled analysis of extension phases of two Phase III trials. Neurogastroenterol Motil. 2014;26(12):1792-1801.

26. Schutter U, Grunert S, Meyer C, Schmidt T, Nolte T. Innovative pain therapy with a fixed combination of prolonged-release oxycodone/ naloxone: a large observational study under conditions of daily practice. Curr Med Res Opin. 2010;26(6):1377-1387.

27. Ueberall MA, Mueller-Schwefe GH. Safety and efficacy of oxycodone/ naloxone vs oxycodone vs morphine for the treatment of chronic low back pain: results of a 12 week prospective, randomized, open-label blinded endpoint streamlined study with prolonged-release preparations. Curr Med Res Opin. Epub May 29, 2015.

28. Hansson L, Hedner T, Dahlöf B. Prospective randomized open blinded end-point (PROBE) study. A novel design for intervention trials. Prospective Randomized Open Blinded End-Point. Blood Press. 1992;1(2):113-119.

29. Cryer B, Li C, Simon LS, Singh G, Stillman MJ, Berger MF. GIREASONS: a novel 6-month, prospective, randomized, open-label, blinded endpoint (PROBE) trial. Am J Gastroenterol. 2013;108(3): 392-400.

30. Deutsche Schmerzgesellschaft. Deutscher Schmerzfragebogen [German Pain Questionnaire]. Berlin: Deutsche Schmerzgesellschaft; 2012. Available from: http://www.dgss.org/deutscher-schmerzfragebogen. Accessed April 10, 2015. German.

31. Deutsche Schmerzgesellschaft. Handbuch zum Deutschen Schmerzfragebogen [Manual for the German Pain Questionnaire]. Berlin: Deutsche Schmerzgesellschaft; 2012. Available from: http://www.dgss.org/fileadmin/ pdf/12_DSF_Manual_2012.2.pdf. Accessed April 10, 2015. German.

32. MST Mundipharma Retardtabletten package insert. Mundipharma GmbH, Germany. February 2015. Available at: https://www.mundipharma.de/fileadmin/mundipharma-relaunch/documents/public/ gebrauchsinformationen/GI_MST_10-30-60-100-200mg.pdf. Accessed July 06, 2015.

33. Oxygesic Retardtabletten. Mundipharma GmbH, Germany. November 2011. Available at: https://www.mundipharma.de/fileadmin/ mundipharma-relaunch/documents/public/gebrauchsinformationen/ GI_Oxygesic_5-10-20-40-80mg.pdf. Accessed July 06, 2015.

34. Targin Retardtabletten. Mundipharma GmbH, Germany. May 2014. Available at: https://www.mundipharma.de/fileadmin/mundipharmarelaunch/documents/public/gebrauchsinformationen/GI_Targin_5mg2_5mg_10mg-5mg_20mg-10mg_40mg-20mg.pdf. Accessed July 06, 2015 .

35. Kassenärztliche Bundesvereinigung; Arzneimittelkommission der Deutschen Ärzteschaft. [Current agents: oxycodone/naloxone] Wirkstoff Aktuell: Oxycodon/Naloxon. Berlin: Kassenärztliche Bundesvereinigung; 2012. German.

36. Rentz AM, Yu R, Müller-Lissner S, Leyendecker P. Validation of the Bowel Function Index to detect clinically meaningful changes in opioidinduced constipation. J Med Econ. 2009;12(4):371-383.

37. Ueberall MA, Müller-Lissner S, Buschmann-Kramm C, Bosse B. The Bowel Function Index for evaluating constipation in pain patients: definition of a reference range for a non-constipated population of pain patients. J Int Med Res. 2011;39(1):41-50. 
38. Deutsche Schmerzgesellschaft: Deutscher Schmerzfragebogen [German Pain Questionnaire]. Available from: http://www.dgss.org/deutscherschmerzfragebogen. German. Accessed July 06, 2015.

39. Frettlöh J, Maier C, Gockel H, Hüppe M. [Validation of the German Mainz Pain Staging System in different pain syndromes]. Schmerz. 2003;17(4):240-251. German.

40. Von Korff M, Ormel J, Keefe FJ, Dworkin SF. Grading the severity of chronic pain. Pain. 1992;50(2):133-149

41. Levine JD, Gordon NC, Fields HL. Naloxone dose dependently produces analgesia and hyperalgesia in postoperative pain. Nature. 1979;278(5706):740-741.

42. Rochford J, Stewart J. Activation and expression of endogenous pain control mechanisms in rats given repeated nociceptive tests under the influence of naloxone. Behav Neurosci. 1987;101(1):87-103.

43. Greeley JD, Lê AD, Poulos CX, Cappell H. "Paradoxical" analgesia induced by naloxone and naltrexone. Psychopharmacology (Berl). 1988;96(1):36-39.

44. Poulos CX, Knoke DM, Le AD, Cappell H. Naloxone-induced analgesia and morphine supersensitivity effects are contingent upon prior exposure to analgesic testing. Psychopharmacology (Berl). 1990;100(1):31-35.

45. Wang HY, Friedman E, Olmstead MC, Burns LH. Ultra-low-dose naloxone suppresses opioid tolerance, dependence and associated changes in mu opioid receptor-G protein coupling and Gbetagamma signaling. Neuroscience. 2005;135(1):247-261.

46. Burns LH, Wang HY. Ultra-low-dose naloxone or naltrexone to improve opioid analgesia: the history, the mystery and a novel approach. Clin Med Insights Ther. 2010:2;857-868.
47. Parolaro D, Sala M, Gori E. Effect of intracerebroventricular administration of morphine upon intestinal motility in rat and its antagonism with naloxone. Eur J Pharmacol. 1977;46(4):329-338.

48. Stewart JJ, Weisbrodt NW, Burks TF. Central and peripheral actions of morphine on intestinal transit. J Pharmacol Exp Ther. 1978;205(3): 547-555.

49. Porreca F, Cowan A, Raffa RB, Tallarida RJ. Ketazocines and morphine: effects on gastrointestinal transit after central and peripheral administration. Life Sci. 1983;32(15):1785-1790.

50. Thörn SE, Wattwil M, Lindberg G, Säwe J. Systemic and central effects of morphine on gastroduodenal motility. Acta Anaesthesiol Scand. 1996;40(2):177-186.

51. Leppert W. The impact of opioid analgesics on the gastrointestinal tract function and the current management possibilities. Contemp Oncol (Pozn). 2012;16(2):125-131.

52. Thomas J, Karver S, Cooney GA, et al. Methylnaltrexone for opioidinduced constipation in advanced illness. N Engl J Med. 2008;358(22): 2332-2343.

53. Slatkin N, Thomas J, Lipman AG, et al. Methylnaltrexone for treatment of opioid- induced constipation in advanced illness patients. J Support Oncol. 2009;7(1):39-46.

54. Kohro T, Yamazaki T. Cardiovascular clinical trials in Japan and controversies regarding prospective randomized open-label blinded end-point design. Hypertens Res. 2009;32(2):109-114.
Journal of Pain Research

\section{Publish your work in this journal}

The Journal of Pain Research is an international, peer-reviewed, open access, online journal that welcomes laboratory and clinical findings in the fields of pain research and the prevention and management of pain. Original research, reviews, symposium reports, hypothesis formation and commentaries are all considered for publication.

\section{Dovepress}

The manuscript management system is completely online and includes a very quick and fair peer-review system, which is all easy to use. Visit http://www.dovepress.com/testimonials.php to read real quotes from published authors. 